\title{
PADLET SEBAGAI PLATFORM PEMBELAJARAN DARING \\ PADA MASA PANDEMI (SEBUAH PANDUAN SEDERHANA)
}

Ditulis oleh Dr. Nofrion, M. Pd Tenaga Fungsional PPG UNP Bidang Akademik Staf Ahli Wakil Rektor 1 UNP Bidang Akademik Email. nofrion@,fis.unp.ac.id Ponsel/WA. 081363310550

\section{A. Pengantar}

Pandemi covid 19 telah memaksa pendidik dan peserta didik untuk melakukan transformasi pembelajaran dari pembelajaran tatap muka/luar jaringan kepada pembelajaran tatap maya/dalam jaringan. Dirjen GTK Kemdikbud RI. Iwan Syahril dalam paparannya saat menjadi Narasumber dalam Webinar Guru Abad 21 mengatakan “...pandemi telah memaksa kita untuk akrab dengan teknologi dan guru adalah orang pertama yang dituntut untuk menguasai teknologi pembelajaran...pandemi di satu sisi memantik kreatifitas guru".

\section{B. Padlet sebagai Platform Pembelajaran Daring}

Banyak platform pembelajaran daring yang digunakan guru selama melaksanakan pembelajaran daring seperti Edmodo, Google Classroom, WA, Zoom Cloud Meeting, Google Meet dan Padlet. Setiap platform pembelajaran daring memiliki kelebihan dan kekurangan. Dalam kondisi saat ini, pilihan platform pembelajaran daring bukan mencari satu yang terbaik namun mencari satu yang paling mungkin dilaksanakan sesuai dengan kondisi di sekolah masing-masing. Demikian juga dengan platform pembelajaran daring Padlet. Padlet adalah salah satu aplikasi Web 2.0 yang saat ini sedang booming selain Blendspace, Slideshare, Voki, Storybird dan lain-lain (Haris et al, 2017).

Padlet adalah platform pembelajaran daring yang bisa disebut sebagai platform pembelajaran daring sinkron karena pendidik dan peserta didik hadir secara bersama pada jam yang sama. Secara sederhana, padlet bisa disebut sebagai papan tulis online yang memungkinkan pendidik dan peserta didik menyampaikan dan membagikan ide-ide/gagasan dan pemikiran baik dalam bentuk teks, foto maupun video. Padlet ini sangat mudah digunakan karena tidak perlu mengunduh aplikasi tertentu dan fitur-fiturnya mudah dipelajari. Selain itu, padlet bisa dioperasikan melalui 
smartphone, tablet, laptop dan komputer. Pengguna bisa memilih padlet versi gratis atau versi berbayar sekitar 40an ribu rupiah/bulan.

\section{Kelebihan Padlet sebagai Platform Pembelajaran Daring}

Terkait dengan pembelajaran, beberapa kelebihan padlet sebagai platform pembelajaran adalah:

1. Tersedia versi gratis

2. Aplikasi tidak perlu diunduh sehingga ramah memori.

3. Padlet mampu menciptakan suasana kelas ril (social presence dan teaching presence) karena pendidik dan peserta didik berada dalam satu waktu.

4. Semua bisa menyampaikan ide dan gagasan dengan menggunakan teks, audio atau video.

5. Pendidik bisa menyajikan perangkat pembelajaran, bahan ajar, daftar hadir, penilaian secara langsung di kolom padlet atau menggunakan link dari web dan google form yang telah disiapkan sebelumnya. Padlet menyediankan fitur tautan yang lengkap.

6. Pendidik bisa menata papan tulis online padlet semenarik mungkin dan menyisipkan aplikasi game edukatif seperti Kahoot atau Mentimeter.

7. Pendidik bisa menata aktivitas belajar lebih variatif berbasis tugas atau proyek secara individu, berpasangan atau berkelompok.

8. Pendidik dan peserta didik bisa berganti peran secara leluasa.

9. Dinamika kelas terekam secara otomatis yang dapat diunduh melalui fitur sharing dan eksport.

10. Pendidik bisa mengelola tingkat berpikir peserta didik mulai dari LOTS, MOTS ke HOTS berbasis PBL maupun PjBL.

Lebih lanjut, beberapa kekuatan padlet sebagai platform pembelajaran daring adalah:

1. Memberi ruang kepada siswa untuk berkolaborasi (Dembo \& Bellow, 2013;Fuchs, 2014; Ellis, 2015).

2. Siswa dapat memberikan input secara aktif dan langsung (Stannard, 2015)

3. Siswa bisa terhubung dengan siswa lain dan memberi masukan.

4. Guru dan siswa mendapatkan bahan umpan balik pembelajaran 
5. Hasil karya pembelajaran Padlet dapat dibagikan ke facebook, Google, Email atau disematkan ke web personal (Wood, 2016).

Selain itu, Padlet bisa menjadi dinding online untuk mengumpulkan berbagai ide dan gagasan dari pengguna secara virtual (Shield, 2014). Para pengguna Padlet dapat membuat dinding dan berkontribusi kepada semua dinding yang ada tanpa batas, menyesuaikan dan mengatur privasi dan berbagi dinding secara resiprokal (Fiester \& Green, 2016;Miller, 2016). Padlet bisa digunakan untuk mewadahi diskusi, curah pendapat dan pengerjaan proyek (Stannard, 2015).

\section{Hasil Riset tentang Implementasi Padlet sebagai Platform Pembelajaran}

\section{Daring}

Beberapa hasil riset membuktikan bahwa padlet dapat meningkat minat belajar dan daya tarik pembelajaran serta meningkatkan kinerja siswa dalam pembelajaran bahasa (Haris et al, 2017) walaupun diperlukan waktu untuk membiasakannya dalam pembelajaran (Redecker, Ala-Mutka, Bacigalupo, Ferrari \& Punie, 2009). Penerapan padlet juga mampu menarik minat dan meningkatkan kemampuan siswa dalam menulis teks deskripsi pada mata pelajaran Bahasa Indonesia (Qulub \& Renhoat, 2020).

\section{E. Langkah-langkah Penggunaan Padlet sebagai Platform Pembelajaran Daring}

Berikut langkah-langkah penggunakan aplikasi Padlet sebagai platform pembelajaran daring.

1. Daftar atau Masuk ke aplikasi Padlet dengan akun pribadi. 


Daftar untuk Padlet
Sudah punya akun? Masuk
G Sign up with Google
If Sign up with Facebook
III Sign up with Microsoft
Email
Email

Password

Password

Aku cantik $\square$

Jika menggunakan akun Google maka bisa masuk dengan Single Sign-On (SSO) tanpa harus mendaftar lagi.

2. Pilih Versi yang Diinginkan (Gratis atau Berbayar)

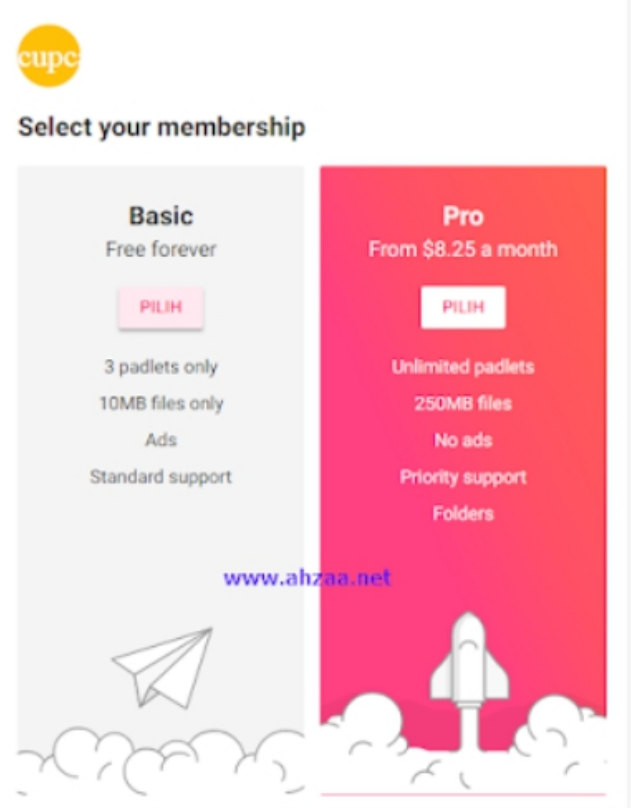

3. Setelah mendaftar maka kita akan landing di halaman utama. 


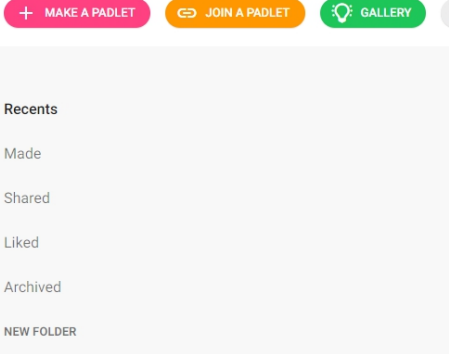

Pada bagian atas terdapat empat kotak dengan warna berbeda. Pada tahap awal kita pilih "Make a Padlet". Di bagian kanan bawah sudah tersedia beberapa pilihan template. Silakan pilih salah satu dengan terlebih dahulu memahami polanya.

4. Silakan pilih desain template padlet dan berbagai pilihan atributnya.

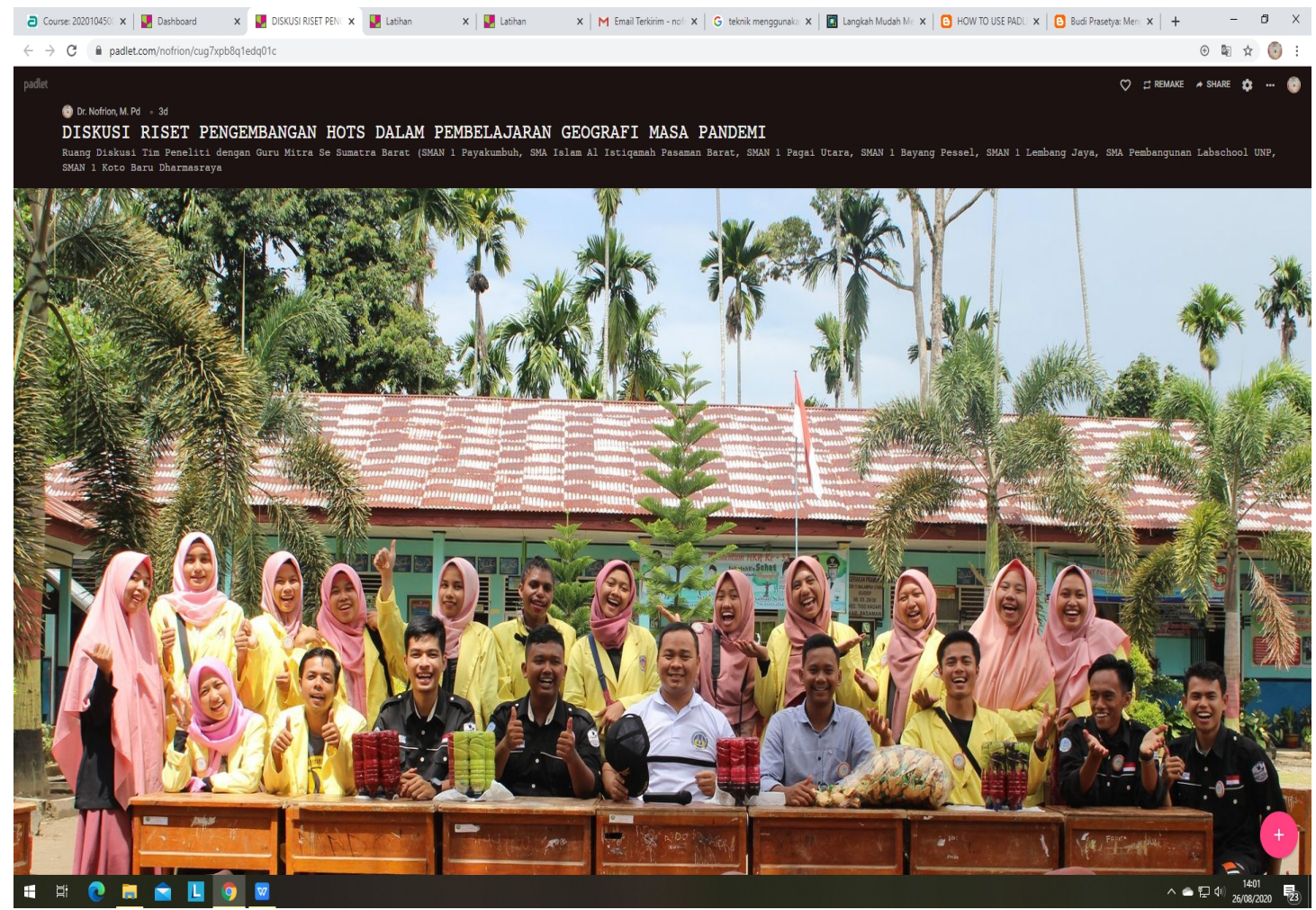

5. Tentukan topik dan berikan penjelasan. 


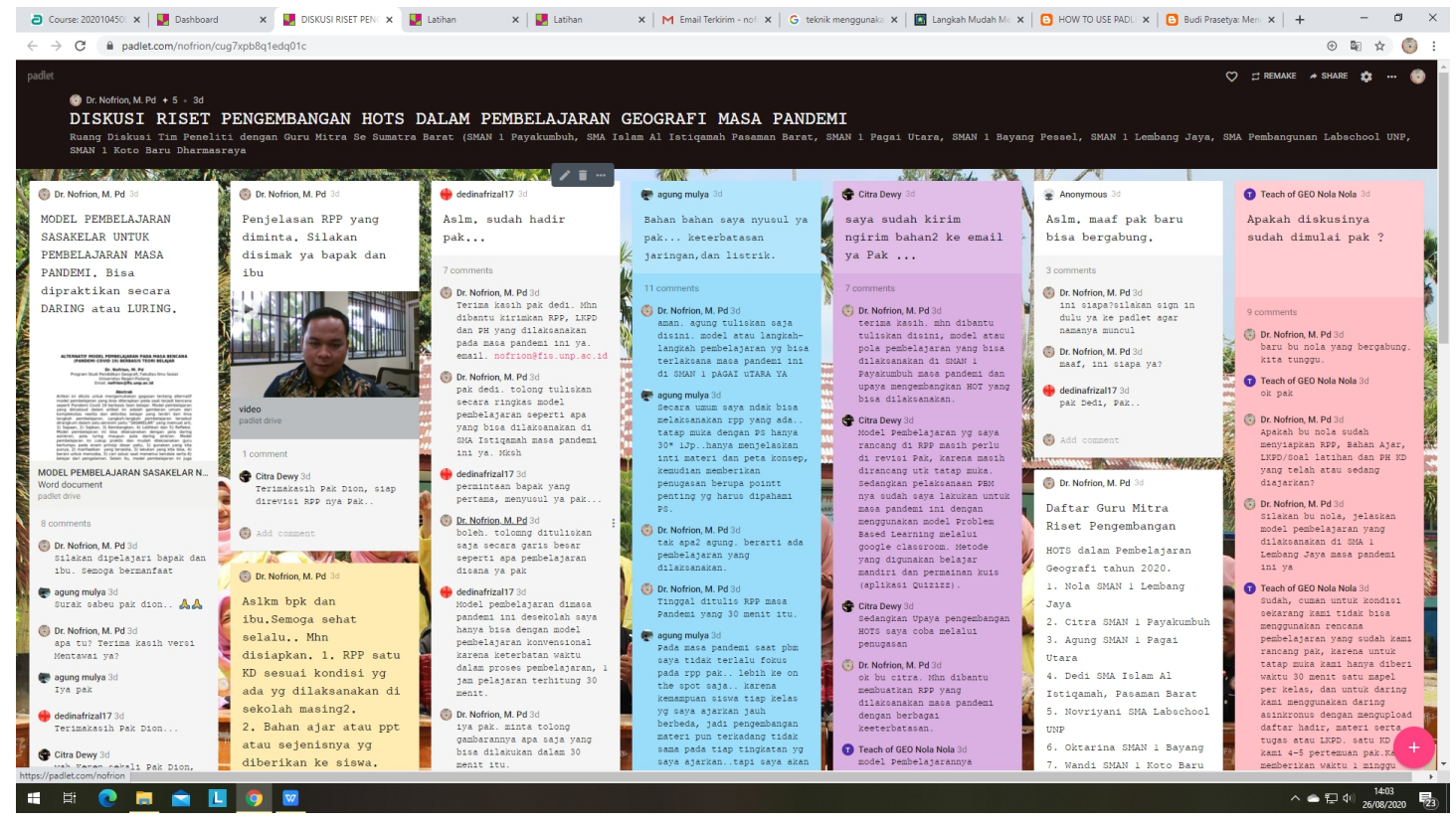

6. Simpan/eksport hasil pembelajaran/diskusi dalam berbagai pilihan seperti pdf, image dan lain-lain.

padlet

padlet.com/nofrion/cug7xpb8q1edq01

DISKUSI RISET PENGEMBANGAN HOTS DALAM PEMBELAJARAN GEOGRAFI MASA PANDEMI

Ruang Diskusi Tim Peneliti dengan Guru Mitra Se Sumatra Barat (SMAN 1 Payakumbuh, SMA Islam Al Istiqamah Pasaman Barat, SMAN 1 Pagai Utara, SMAN 1 Bayang Pessel, SMAN 1 Lembang Jaya, SMA Pembangunan Labschool UNP, SMAN 1 Koto Baru Dharmasraya

DR. NOFRION, M. PD AUG 23, 2020 02:56PM

DR.

MODEL PEMBELAJARAN SASAKELAR UNTUK PEMBELAJARAN MASA PANDEMI.

Bisa dipraktikan secara DARING atau LURING. APA YANG TLNSEDIA, APA YANC ADA. Trake perlu terbelenggu dengan sintak model 2 tertentu. kemau pembelajaran yang disederhanakan dalom hal sintab, turing ruang lingkup dan tagihan. Intinya, kita tetap beruscha tonpe harus memaksanakan diri. - DR. NOFRION, M. PD Iya Pak, siap dicoba Pak - CITRA DEWr

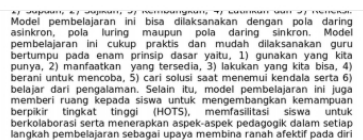

Kata Kunci : Model Pembetajaran SASAKELLR, Pandemi Covid

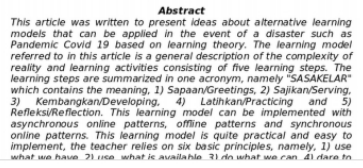

MODEL PEMBELAJARAN SASAKELAR NOFRION 2020 MAA PANDEMI

Word document

PADLET DRIV

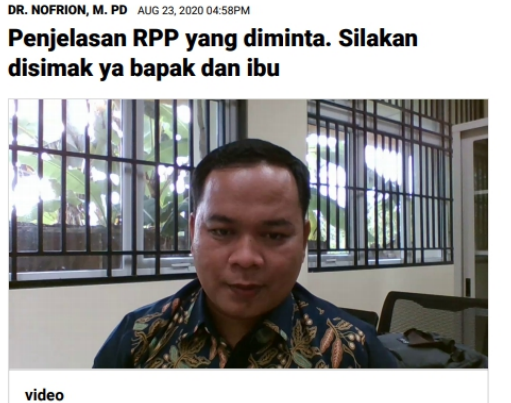




\section{F. Penutup}

Padlet dapat dijadikan sebagai salah satu platform pembelajaran daring pada masa pandemi. Penggunaan padlet dapat disesuaikan dengan kualitas jaringan internet di tempat guru dan siswa melalui penyesuaian pada bentuk respon. Jika kualitas jaringan internet kurang kuat maka respon siswa diminta dalam bentuk teks. Jika kualitas jaringan internet semakin kuat maka respon siswa bisa ditingkatkan dalam bentuk audio dan video. Kehadiran padlet menambah pilihan bagi guru untuk menyajikan pembelajaran daring. Dengan berbagai kelebihan-kelebihan yang dimiliki padlet sebagai platform pembelajaran daring diharapkan agar pembelajaran dapat terlaksana dengan efektif walaupun dalam masa pandemi covid 19. Lebih lanjut, penggunaan padlet dalam pembelajaran dapat dijadikan sebagai wadah kolaborasi antar guru baik sesama guru mata pelajaran maupun antar mata pelajaran. Hal ini juga relevan dengan "silent revolution" yang menjadi ciri komunitas belajar dalam Lesson Study for Learning Community/LSLC).

\section{DAFTAR RUJUKAN}

Dembo, S.E. \& Bellow, A.S. 2013.Untangling the Web: 20 Tools to Power Up Your Teaching. SAGE, London

Ellis, D. 2015. Using Padlet to Increase Engagement in Lectures. Paper presented at the195-XIII Retrievedfro httpsearch.proquest.comdocview1728004496accountid=146458.

Fiester, H. \& Green, Tt. 2016.Student use of backchannels. TechTrends 60(4): 404-408.Doihttpdx.doi.org10.1007s11528-016-0069-9.9.

Fuchs, B. 2014. The writing is on the wall: using Padlet for whole-class engagement. LOEX Quarterly 40(4), 7-9. Retrieved from http://uknowledge.uky.edu/libraries_facpub/240

Miller, K. 2016. Tech Bits.College \& Research. Librarires News 77(3):109

Munirah, Haris. Melor Md. Yunus, Jamaludin Hj. Badusah. 2017. The Effectivieness of Using Padlet in ESL Classroom. International Journal of Advanced Research (IJAR) Volume 5 Nomor 2, Halaman 783 - 788.

Nofrion, N. (2019, May 14). FLIP YOUR CLASSROOM: FLIPPED CLASSROOM MELALUI PENERAPAN MODEL PEMBELAJARAN EXO OLO TASK. https://doi.org/10.31227/osf.io/qb9wz

Nofrion, N. (2019, August 24). Metode Jumping Task untuk Mengembangkan Keterampilan Berpikir Tingkat Tinggi (HOTS) dalam Pembelajaran. https://doi.org/10.31227/osf.io/2q6bp 
Qulub, Tathmainnul \& Renhoat, Fauziyah, Syifa. 2020. Penggunaan Media Padlet untuk Meningkatkan Keterampilan Menulis Teks Deskriptif. Prosiding SAMASTA, Juni 2020. Halaman $1-5$

Redecker, C., Al-Mutka, K., Bacigalupo, M., Ferrari, A. \&Punie, Y. 2009. Learning 2.0: the impact of Web 2.0innovations on education and training in Europe. Final Report, Seville: European Commission-Joint ResearchCenter-Institute for Pospective Technological Studies

Shield, J. 2014.Virtual Toolkit. Screen Education 75:92-93

Stannard, R. 2015. Webwatcher. English Teaching Professional 97:67

Wood, M. 2016. Padlet a graffiti wall for today's agricultural teacher. Agricultural Education 